UNIVERSITA' DEGLI STUDI DI BERGAMO

DIPARTIMENTO DI INGEGNERIA GESTIONALE

QUADERNI DEL DIPARTIMENTO ${ }^{\dagger}$

Department of Economics and Technology Management

Working Paper

n. $08-2012$

Two short essays on Mark Blaug's last intellectual battles

by

Andrea Salanti

${ }^{\dagger}$ Il Dipartimento ottempera agli obblighi previsti dall’art. 1 del D.L.L. 31.8.1945, n. 660 e successive modificazioni. 


\section{NOTE}

I Working Papers della Collana dei Quaderni del Dipartimento di Ingegneria Gestionale costituiscono un servizio atto a fornire la tempestiva divulgazione dei risultati dell'attività di ricerca, siano essi in forma provvisoria o definitiva.

I Working Papers della Collana sono pubblicati nell'archivio istituzionale dell'Università degli studi di Bergamo (Aisberg): http://dspace-unibg.cilea.it/handle/10446/370. 


\title{
Two short essays on Mark Blaug's last intellectual battles
}

\author{
Andrea Salanti ${ }^{1}$
}

December 2012

\begin{abstract}
In the last period of his professional life Mark Blaug (1927-2011) repeatedly intervened with a series of papers characterised by a critical attitude towards both Whig history and the formalist turn in modern economics. At the same time, however, he never abandoned his long standing commitment to Lakatosian methodology. The two papers which follows have in common the aim of showing that the same critical conclusions can be better served by more updated methodological approaches.
\end{abstract}

\footnotetext{
${ }^{1}$ Department of Economics and Technology Management, University of Bergamo, Italy. E-mail: andrea.salanti@unibg.it
} 


\title{
Between the Scylla of Whig History and the Charybdis of Methodological Vacuum*
}

\section{The "vicious circle"}

Among the conclusions of Mark Blaug's 1976 prominent exploration of the possibility of applying Lakatos's historiographic suggestions to the history of economics we may find the following bold endorsement of Lakatos's metahistorical research programme:

To be convincing, the externalist thesis in the history of ideas must produce instances of (i) internally consistent, well corroborated, fruitful and powerful scientific ideas which were rejected at specific dates in the history of a science because of specific external factors, or (ii) incoherent, poorly corroborated, weak scientific ideas which were in fact accepted for specific external reasons. I can think of no unambiguous examples of either (i) or (ii) in the history of economics and therefore conclude that a Lakatosian 'rational reconstruction' would suffice to explain virtually all past success and failures of economic research programmes. (Blaug 1976, 179, italics added),

A quarter century after, however, in a paper by the same author we come across an entirely different assessment of the differences between "rational" and "historical" reconstructions:

\begin{abstract}
Some historians of economic thought have tried to sell the subject to their departmental colleagues by reducing history of economic thought to the history of economic analysis, and then by dressing up past ideas in modern garb, often in the form of mathematical models [...] I call these "rational reconstructions" and I contrast them with "historical reconstructions" [...] Although I have been guilty myself of the very sin I have just deplored, I have come to the conclusion that the only approach to the history of economic thought that respects the unique nature of the subject material, rather than just turning it into grist for the use of modern analytical techniques, is to labor at historical reconstructions, however difficult they are. (Blaug 2001, 150-2) ${ }^{1}$
\end{abstract}

\footnotetext{
*Forthcoming in a volume in memory of Mark Blaug, edited by Marcel Boumans and Matthias Klaes, to be published by Edward Elgar.

${ }^{1}$ In the middle, not only chronologically, we may found an intermediate position on the same matters: "If one must choose between two polar opposites, I hold that 'absolutism' is more defensible than 'relativism', particularly as strict 'relativism' is logically impossible. [...] however much there is a genuine distinction to be made between these two styles ['moderate relativism' and 'strict absolutism'] in the historiography of economics, they tend invariably to shade into one another: what is in principle separable is in practice almost inseparable. (Blaug 1990a, 28-9) See also, in the same vein, Blaug (1994a, 17-18).
} 
A comprehensive evaluation of the reasons behind a so evident change of attitude towards the historiographic question, and its consequences for his well-known methodological commitments, is probably a task to be left to future scholars willing to reconstruct his whole intellectual biography. For the time being John Davis (2012) offers us a sensible reconstruction of both the contingent reason which prompted Blaug to modify his historiographic creed (the search for arguments suited to contrast the profession's dismissive attitude toward the history of economic thought), and the kind of arguments he drew on in order to justify his change of perspective (essentially a rejection of the metaphor of the "marketplace of ideas" in favour of an evolutionary view of economic knowledge emphasizing the presence of path-dependency in the history of economic thought).

Davis's interpretation surely sheds some light on Blaug's second thoughts about the historiography of economics. It remains to be seen, however, how all this could be reconciled with the reiterated methodological positions of an author who regarded himself as an admittedly unrepentant Popperian (Blaug 1994b) and many fellows would regard as an unrepentant Lakatosian (see, for instance, Boumans 2012). In this respect a number of intriguing questions immediately come to my mind as deserving further reflections.

To begin with, think of the different attitudes among "historians" and "methodologists" about Lakatos's methodology that became apparent at least since the 1989 conference in Capri $^{2}$, where mainly methodological assessments of the Lakatosian methodology of scientific research programmes (MSRP) were predominantly negative in their conclusions, but at the same time a number of detailed reconstructions of specific subfields of economics relied on typically Lakatosian characterisations of the involved research programmes. Methodologists' critical attitude was surely due, among other things, to the difficulties encountered in their attempts at identifying progressive research programmes within economics. Historians, in contrast, seemed to rely on the Lakatosian notion of research programme mainly in order to identify portions of economic analysis whose historical development could be rationally reconstructed.

\footnotetext{
${ }^{2}$ The published outcome of that conference can be found in de Marchi and Blaug (1991) and in three papers (Collins 1991, Knorr-Cetina 1991 and Cartwright 1991) appeared in HOPE as a "minisymposium".
} 
Blaug (1991a) reacted by pointing out the "subtle distinction in Lakatos" between MSRP and MHRP (the methodology of historiographical research programme) ${ }^{3}$ and admitting in this respect that:

There is ... no inherent connection between MSRP and MHRP and it may well be that the former is true and the latter is false. Thus ... I argued that modern economists preach the methodology of falsificationism but rarely practise it ... This thesis may be expressed by saying that in economics MHRP is largely false; however that in no way denies the force of MSRP; the normative case for falsificationism might stand up even if the positive one fell to the ground (1991a, $503)^{4}$

I regard this "subtle distinction" as an undoubtedly wise argument if its scope is to find a possible justification for retaining a Lakatosian methodological attitude with reference to economics. It turns out to be less convincing, however, if we adopt it as a historiographic perspective. Indeed, of what use might be MSRP in the hand of an historian of a discipline if its practitioners usually do not follow the falsificationist prescriptions (as Blaug himself admits of economists)? If nevertheless we encountered "progressive" research programs, we should have to explain these unintended consequences of scientists' behaviour. In a few cases this may well be done without much difficulty: a good case in point is surely the Keynesian revolution. In this case, indeed, Blaug was quite successful in showing its progressiveness (at least during the 1930s and 1940s) along Lakatosian lines. I think, in other words, that Blaug (1990b and 1991b) was essentially right contra Hands (1985 and 1990).

The same cannot be said, however, with reference to the other obvious candidate for the same exercise, namely the research programme connected with the Walrasian general equilibrium theory. If we agree with Blaug on the impossibility to detect any form of meaningful (empirical) progress within this programme, then we face the problem of explaining why it has been for a long time held in so high esteem by the economists' profession. We should explain, in other words, why a degenerating

\footnotetext{
${ }^{3}$ MSRP is summarized as consisting of the thesis that the evolution of an SRP (made up of a hard core and a protective belt) "should be appraised in terms of excess empirical content", while MHRP is depicted as "the quite distinct historical thesis that scientists in fact adopt and reject SRPs in accordance with that appraisal criterion" (Blaug 1991a, 502).

${ }^{4}$ For a summary of Blaug's interpretation of Lakatos' methodology of scientific research programmes, see also Blaug (1998).
} 
programme like this is/has been endorsed by the overwhelming majority of economists for decades.

Facing this problem, coherently with this methodological creed, Blaug repeatedly dismissed general equilibrium theory (and game theory, for that matter) as an empirically irrelevant construction which he regarded as the bad fruit of economists suffering from mathematical envy (see, for instance, Blaug 1992, chapter 8). On the other hand, on the grounds of the same methodological judgment he maintained that what constitutes good economics and good methodological practice is primarily Marshallian-based microeconomics and Friedman-style macroeconomics. However, having explicitly abandoned MHRP at least since the early 1990s, and the historigraphic preference for rational reconstructions ten years later, his reiterated indictments of the formalist vice does not seem to be grounded on a completely appropriate methodological background, apart from the plain and simple advocacy of falsificationism as a normative methodology that economists should seriously try to put into their practice to the advantage of the relevance of the discipline.

It is not accidental, in my opinion, that in a number of papers dealing with the notion of progress (Blaug 2002a) and the formalist vice in economics (Blaug 1999, 2002b, 2003) explicit references to Popperian/Lakatosian themes are almost absent ${ }^{5}$. From the reading of these papers one might be tempted to conclude that Blaug got to some extent caught in the trap that he himself had so cogently identified when he observed, a propos of "methodology versus history", that:

We appear, therefore, to be caught in a vicious circle, implying the impossibility both of a methodologically-free, totally descriptive historiography of science and an ahistorical, purely prescriptive methodology of science. From this vicious circle there is, I think, no real escape (Blaug 1992, 31)

Probably there is not a real getaway from this dilemma, but I think that those who agree with Blaug's disapproval of so much sterile formalism in modern economics ought to put some efforts into exploring alternative ways of dealing with this issue, looking more closely at the way in which economics is actually practiced.

\footnotetext{
${ }^{5}$ Even when dealing with "rigor vs. relevance" (Blaug 2009a), as I tried to show in Salanti (forthcoming), methodological arguments do not appear to have been completely developed.
} 
Saying this does not necessarily imply, to be sure, an endorsement of one of the radical versions of the so-called "naturalistic turn" in present-day epistemology, with their refusal of any methodological prescription. Rather, it suffices to recognize the advantages to be gained from paying more attention to the actual scientific practices. ${ }^{6}$ It is enough, in other words, to recognize some merits to what Hands $(2001,132)$ has dubbed "reformist naturalism", a perspective that "employs science to reform epistemology; the traditional epistemological questions remain the same, science just provide a new set of answers/solutions". 7

Take, for instance, one of Blaug's repeated dismissals of game theory:

[G]ame theory has turned out to be an even more seductive technique for economists than general equilibrium theory, encouraging once again the persistent tendency of modern economists to look away from the world and engage instead in arm-chair deductive theorizing. [...]

In the field of industrial organization, which has been more systematically colonized by game theory than any other branch of economics, its principal effect has been to pour old wine in new bottles: it is difficult, nay, impossible, to think of a single novel observation that has come out of the "new" industrial organization infused by game theory that was not already part-and-parcel of the "old" industrial organization ..." (Blaug 2002b, 39-40) ${ }^{8}$

In all fairness to him and with all due respect for his intellectual honesty, it should be apparent that statements of this kind are neither historically accurate, nor methodologically informative. We may well be sympathetic to Blaug's overall judgment on game theory in industrial economics, but we should not avoid thinking about the reasons why so many fellow economists are currently engaged in developing such a kind of models. In the following sections I will try to show that in any case something can be learned by looking at what economists actually do, with reference to a couple of examples from (applied) game theory. Conclusions may well remain critical

\footnotetext{
${ }^{6}$ Even if in more orthodox Lakatosian terms, Boumans (2012) seems to raise a similar point when he comments "Blaug had, unfortunately, an almost blind spot for the $20 \%$ Lakatos that was Lakatos, the historian and philosopher of mathematics." (p. 14).

${ }^{7}$ Note that observing scientific practice does not imply, per se, that we are obliged either to assume perfect rationality of single scientist/scientific communities, or to rely on some version of the metaphor of the "marketplace of ideas". In other words, we are not compelled to justify whatever practice we might meet in a certain discipline. To do this, however, we need some criteria of methodological judgment and therefore we cannot completely avoid some normative methodological prescriptions (if only implicitly adopted).
}

\footnotetext{
${ }^{8}$ In a similar vein, see also Blaug (1992, 240-241; 1994b, 128-129; 2003, 148-150)
} 
of the current state of economics, but along the way some understanding of the reasons behind such practices can nonetheless be gained.

\section{Two examples from (applied) game theory}

As a first case in point, let us take the theory of imperfect competition. The volume edited by Gabszewicz and Thisse (1999) - a reference collection of essays ranging from the classic analyses of Cournot, Edgeworth and Chamberlin, to the most important contributions of the 70's and the 80's - is particularly suited to our purpose. Since the early pioneering contributions to this field it clearly emerged that the problem of modeling agents' conjectures may receive a plurality of answers, each one with its own pros and cons. Even nowadays the number of different representations of the situation facing the imperfectly competitive firm is portentous, and in different models we may find exactly the opposite specification of the game that the agents are supposed to play.

Let us consider, in particular, two models that employ two-stage oligopolistic games. Kreps and Scheinkman (1983) consider the case of perfectly substitutable commodities as a game with quantity precommitment in the first stage and price competition in the second. All this is done in order to show that, under appropriate assumptions, there exists a unique equilibrium of Cournot-like type. Benassy (1986), who is instead concerned with product differentiation, investigates the existence of Bertrand-Edgeworth equilibria with differentiated commodities. After having approvingly referred just to the previous article as "a recent and interesting contribution on timing in the pure substitutes case" (n. 6, 58), in the last section of his paper he presents a two-stage game where "the idea is that agents choose prices in a first stage, and then production in a second stage" (72, italics added).

Having different structures of game seemingly capable to deal with the same situation prevent us to rely on sound explanations of what is at stake. To identify a single mechanism, however, might reveal to be a far from easy task if, as some social scientists would be prepared to recognise, different mechanisms may be concurrently at work in the real world. It is tempting, therefore, to conclude that "when the competitive paradigm is abandoned, and replaced by more realistic assumptions"; the new paradigm will look like a "highly coloured patchwork of often unrelated 
investigations". This will be necessary "[to] mirror the incredible complexity of real market phenomena" (Gabszewicz and Thisse 1999, p. lii).

Deriving equilibrium solutions under different assumptions about the structure of the game used to investigate a specific situation is nowadays considered a research activity worthy to be pursued. This becomes even more evident when we consider more narrowly circumscribed subjects. Take, for instance, the issue of "vertical separation" (between manufacturers and retailers). Bonanno and Vickers (1988) discuss the profit incentive for a manufacturer to sell his product through an independent retailer rather than directly to consumer, by means of a duopoly model under the assumption that a franchise fees can be applied by the manufacturer in order to extract retailers' surplus. The main conclusion they reach by means of this model is that:

the two-stage game in which first manufacturers choose wholesale prices ... and then retailers compete in retail prices, has a unique perfect equilibrium at which both manufacturers choose vertical separation and charge wholesale prices in excess of production costs, provided franchise fees can be used to extract retailers' surplus. (263)

Their concluding remarks are rather cautious. After having reminded that they considered the case of two manufacturers each of whom has one retailer, the two authors look forward to the next step as the a study of the general case with " $m$ " manufacturers each of whom with " $n$ " retailers. Moreover, they recognize that

The well-known literature on strategic commitment examines several other ways of seeking to achieve the same end (including, for example, strategic investment in capacity or R \& D to alter costs), and an important question for future research concerns the relative merits of these various instruments. In reality, vertical separation does not operate costlessly ... There may be costs of information and coordination, and franchise fees cannot always be used to extract retailers' profits fully. However, vertical separation has some advantages as a method of commitment. ... We therefore believe that vertical separation - and vertical arrangements between manufacturers and retailers more generally - deserve some consideration from a strategic viewpoint. (264)

So far, so good, one might say, were it not that twenty-four years later, in a much longer paper published on one of the leading economic journals (Pagnozzi and Piccolo 2012), we find again two manufacturers each of whom with her own retailer. The importance of the previous result is lessened by observing that it depends upon the assumptions of public (that is, observed by competitors) contracts between 
manufacturers and retailers, while "when contracts are private (or, alternatively, when publicly announced contracts can be secretly renegotiated), a manufacturer's wholesale price cannot affect the strategy of a rival retailer"(173) so that one may conclude - as indeed previously maintained in some contribution to this literature - that delegation does not have any strategic effect (because in equilibrium the wholesale price equates the marginal cost of the manufacturer) and therefore is neutral. The aim of the authors is to demonstrate that:

[T] he neutrality result rests on a specific assumption about retailers conjectures on their competitors contracts - i.e. passive beliefs - and that the equilibrium changes when alternative, but equally reasonable, assumptions are considered. The point is that, with private contracts, a retailer's strategy depends on his conjecture about the wholesale price paid by rival retailers and this conjecture may depend on the contract offered to the retailer. Hence, even if vertical separation cannot directly affect the strategies of rival retailers, it can still affect a retailer's conjecture about his rivals input cost (as well as the retailer's own input cost).

From their analysis it emerges that if retailers have symmetric (or at least not completely passive beliefs) the manufacturers are better off with vertical separation, regardless of the nature of competition (on prices or on quantities) in the retail market. So we remain with the (unanswered) questions: is vertical separation under franchising agreements (frequently detectable in the real world, especially for some product categories) to be interpreted as due to public contacts (and therefore complete information) or to private contracts plus symmetric beliefs? And again, if with passive beliefs vertical separation come out to be unsuited to increase the profit of the manufacturers, have we to look elsewhere for an explanation (for instance in terms of different costs of transaction and control)?

\section{A glimpse into up-to-date methodology}

What could we learn, methodologically speaking, from the previous examples (or from similar ones that might be easily found in abundance within current microeconomic literature)? The most apparent fact to be explained is surely the huge proliferation of models within the discipline, so that modern economics (and other cognate disciplines, for that matter - see Frigg and Hartmann 2009) can be actually regarded as a collection of exercises in developing models. For a long period the most common justification of such an overprovision of models in virtually all the subfields of the discipline would 
have probably been framed in terms of economists' hunting for expanding the empirical domain of their pivotal models, or for generalizing their favored theoretical principles.

Methodological debates are historically situated, so that it might well be that explanations like these had had some merits at that time. Since then, however, many things are changed, either in the nature of most economic models as they can be found in current literature, or in those methodological approaches which have recently become increasingly popular among philosophers of science. One of the tenet of the so called "received view", that was dominant among philosophers of science during the 1950s and the 1960s, was a sort of disdain for the role of models in science, this because logical empiricists regarded scientific theories mainly as collections of sentences susceptible of logical analysis and the related models as having at most a heuristic role to play. It is not at all surprising, therefore, that one of the consequences of its dismissal has been, among other things, a renewed interest in the role of models in the various scientific fields (economic methodology being by no means an exception) ${ }^{9}$.

Within economics it has been repeatedly remarked that in many cases we witness a lot of efforts devoted to deriving similar results from slightly different alternative sets of assumptions, so that we have as a result a huge proliferation of abstract models within the discipline. Differently from traditional accounts, current explanations of this state of affairs look at the "search for robustness" ${ }^{10}$ in order to find a justification for such (otherwise somewhat perplexing) widespread practice. As Kuorikoski et al. (2010, 541) aptly summarizes at the outset of their interesting contribution:

Modern theoretical economics largely consist of building and examining abstract mathematical models. A substantial portion of this modelling activity is devoted to deriving known results from alternative or sparser modelling assumptions [...] The key to understand this practice is, we propose, to view it as a form of robustness analysis, in other words as the systematic examination of the robustness of modelling results with respect to particular modelling assumptions.

In this perspective the abundance of models is interpreted as the outcome of repetitive attempts to establish the robustness of the conclusions so attained by comparing results obtained by different arrays of particular modeling assumptions. The idea is that in this

\footnotetext{
${ }^{9}$ For a summary of how the perspective on models among the philosophers of science changed over time, see Bailer-Jones (1999),

${ }^{10}$ Woodward (2006) is a good survey of the different notions of robustness, warning against possible confusions among them.
} 
way we should obtain "robust" results, in the sense that they do not depend on the details of the particular (and often unrealistic) assumptions employed ${ }^{11}$. According to Gibbard and Varian (1978, 674-5, italics in the original), models can help in understanding a situation

[B]y yielding conclusions that are robust, in the sense that they do not depend on the details of the assumptions. When a theorist applies a model that caricatures a situation, one hypothesis he may entertain is this: the conclusions of the applied model roughly depict some features of the situation, and that is because (1) the assumptions of the model caricature features of the situation, and (2) the conclusions are robust under changes in caricature. A principal way of testing this hypothesis may be to try out models with disparate caricatures of the same complex aspect of reality.

These and other remarks in the same essay suggest that the kind of robustness they have in mind has to do with changes in the model's "idealizations". One idealizes by describing a real-world feature in a very specific, sometimes even extreme or idiosyncratic, fashion. An aspect of the model is characterized so as to instantiate just one of the various forms that that feature can take in the real world. The progressiveness associated with increasing robustness to changes in idealisations should be apparent. The idea is that a given result may well have been rigorously demonstrated with respect to a very specific model-economy only for reasons of simplicity, clarity, or mathematical tractability, but the validity of the result itself should not depend on any of the specific idealisations used in the proof.

Economists seem to use abstract theoretical models instead of (or alongside) painstaking descriptions of specific situations precisely because they hope that a certain causal mechanism is at least relatively robust to changes in the background circumstances, the boundary conditions etc. An important function of theoretical models of the above kind is to provide concrete examples of the way in which causal relations

\footnotetext{
${ }^{11}$ The search for robustness as a reasonable strategy for the construction of theoretical model was firstly advocated by the biologist Richard Levins (1966 and 1968). Among biologists the debate on this matter is still alive: see, for instance Wimsatt (1981 and 1987) and Weisberg (2006a and 2006b). Gibbard and Varian (1978), who have provided one of the first philosophical accounts of economic modeling that makes explicit use of the concept of robustness, characterize an important class of models as "caricatures". More recently, comparable conclusions about the role of models have been reached following a different (but not incompatible) intuition, which look at models mainly as tools for analogical inferences (see, for instance, Gilboa et al. 2012).
} 
can hold between factors or variables. This is done by constructing artificial worlds in which such relations hold, and by demonstrating that they do therein. However, when robustness is referred to changes in the causal mechanism itself, its virtue is far from obvious: it is indeed not so clear how could we identify progress with the proliferation of models featuring different causal mechanisms.

The proliferation of models of this kind might be interpreted as evidence of our inability to detect the best representation of the situation we want to investigate and/or the true mechanism at work. Usually the problem is not a complete lack of some form of empirical evidence, but the lack of decisive evidence. So how can the robustness of a result to radical changes in the theoretical causal mechanism that produced it be considered progressive? For each real-world situation, at most one of these models can tell the true causal story; the fact that we have many alternatives converging on the same result (and sometimes even this does not hold) does not, per se, imply that we are getting closer to the truth. ${ }^{12}$

Perhaps many economists rely on an argument of the same sort as that used for robustness to changes in idealizations: if conclusions do not change very much under different assumptions, this means that that particular detail is not so important after all. In some cases, this may be true: if the only aim is to predict, assuming that nothing much will change in the institutional set-up, an instrumentalist attitude might even be somewhat justified. But in many other circumstances a "detail" such as the kind of game that agents are supposed to play is very important. This is surely the case when it comes to intervention, for example when the legislator intends to implement some sort of regulation. Very often, indeed, only the knowledge of the structure of the game will allow us to predict the ways in which the agents will react to a change in rules and/or incentives.

The problem is that not infrequently we have many different structures of games employed to deal with more or less similar situations. By changing a number of assumptions here and there, we may surely check which ones can be dispensed without

\footnotetext{
${ }^{12}$ For an essentially identical argument in an empirical context, see Cartwright (1991). In the terminology of Backhouse (1997, 100-1), we may say that robustness to the causal mechanism increases the generality of a result, but diminishes its scope, where the "scope" is the class of identifiable situations of applicability.
} 
affecting the main results, but at the same time we give up the possibility of identifying the "true" causal mechanisms at work. By so doing, indeed, we cannot infer from the observation of empirical regularities (even when luckily detectable), satisfactory explanations, in the true meaning of the word, of what makes them happen At most such exercises can be taken as attempts, either to check the appropriateness of a certain analytical technique in dealing with a number of issues within a specific subfield of the discipline, or to corroborate some "general" principle, for instance about the relationship between information and competition $^{13}$ : in any case a too meagre result in comparison with the huge amount of efforts currently devoted to such a kind of "scientific" activity.

\section{Final remarks}

After Blaug's recantation of the usefulness of "rational reconstructions" in the making of history of economic thought, the very question which should be answered, simply put, is: "what kind of (economic) methodology should be adopted to support "historical reconstructions"? The title chosen for this paper intends to suggest that an answer is needed in order to avoid the treat of making history in a methodological vacuum, something that Blaug repeatedly insisted should not have to be done in any case.

Admittedly, I do not own a comprehensive solution, but is there somebody around who gets it? What I have tried to suggest, more modestly, is that we should not a priori reject all the tenets of the so-called naturalistic turn in epistemology. In particular we should retain the advice to pay more detailed attention to what researchers actually do. This does not necessarily imply, however, that we have to justify whatever scientific outcome we may come to face in a particular discipline: the final judgment will depend on our background methodological beliefs, after all.

In the last decade or so of his more than respectable career Mark Blaug repeatedly protested against the excess of formalism in modern economics. I am sympathetic with his main conclusion, but the problem, as I see it, is that it is not enough to point out the

\footnotetext{
${ }^{13}$ For example Pagnozzi and Piccolo $(2012,176)$ observe, among other things, that their results "suggest that, if retailers have symmetric beliefs, manufacturers may agree to keep information about wholesale prices private, precisely when public contracts would enhance consumer welfare by reducing retail prices. Hence, allowing retailers to obtain information about their rivals' wholesale prices may actually increase competition".
} 
irrelevance of any theory with no empirically sound implications or at least potentially falsifiable consequences, because it would be all too easy for opponents to raise objections about Popperian falsificationism, mainly on the basis that a strict application of falsificationist criteria either would leads us to discard a too huge amount of current economic theory, or would leave unanswered the question of the multiplicity of theoretical approaches in economics embedded in so many different strands of heterodoxy. But it would be a pity if, frustrated by the inconclusiveness of our methodological appraisals, we were to lose sight of the justified worries about the "ugly currents" in present-day economics. After all, Blaug (2002b, 45) has a surely good point when he remarks:

Policy questions are inextricably woven into the very fabric of economics and for that reason we never can avoid asking: Do we have any good reasons for thinking that economic theories are either true or false in the sense that it makes a difference for economic policy whether we act on the basis of one economic theory or another? Are some economic theories more true than others?

My answer to both of these questions is: "yes."

These are really substantial issues. I think that, for all who agree with the two affirmative answers above, the methodological arguments on which each of them chooses to rely in order to justify such answers ought to be regarded somewhat as "details". In any case, the more updated and generally agreed are such arguments, the higher will be the chance of supporting the really relevant issues at stake. 


\section{References}

Backhouse, Roger E. 1997. Truth and Progress in Economic Knowledge, Cheltenham: E. Elgar.

Bailer-Jones, Daniela M. 1999. "Tracing the development of models in the philosophy of science", in Lorenzo Magnani, Nancy J. Nersessian and Paul Thagard (eds.), ModelBased Reasoning in Scientific Discovery, Dordrecht: Kluwer, 23-40.

Benassy, Jan-Pascal. 1986. "On the existence of Bertrand-Edgeworth equlibria with differentiated commodities", in Werner Hildenbrand and Andreu Mas-Colell. (eds.), Contributions to Mathematical Economics. Essays in Honour of Gérard Debreu, Amsterdam: North-Holland, 57-78 [Reprinted in Gabszewicz and Thisse, 1999, 117 138]

Blaug, Mark. 1976."Kuhn versus Lakatos or paradigms versus research programmes in the history of economics", in Spiro Latsis (ed.), Method and Appraisal in Economics, Cambridge: Cambridge University Press, 149-180.

1990a. "On the historiography of economics" Journal of the History of Economic Thought, 12(1): 27-37.

. 1990b. "Reply to D.Wade Hands's 'Second thoughts on "Second thoughts": reconsidering the Lakatosian progress of The general theory', Review of Political Economy, 2(1): 102-104

. 1991a. "Afterword", in Neil de Marchi and Mark Blaug (eds.), Appraising Modern Economics. Studies in the Methodology of Scientific Programs, Aldershot: E. Elgar, 499-512.

. 1991b. "Second thoughts on the Keynesian revolution", History of Political Economy, 23(2): 171-192.

1992. The Methodology of Economics. Or How Economists Explain, $2^{\text {nd }}$ revised edition, Cambridge: Cambridge University Press.

1994a. "Not only an economist - Autobiographical reflections of a historian of economic thought", The American Economist, 38(2):12-27.

. 1994b. "Why I am not a constructivist: Confessions of an unrepentant Popperian", in Roger E. Backhouse (ed.), New Directions in Economic Methodology, London: Routledge, 109-136.

1998. "Methodology of scientific research programmes", in John B. Davis, D. Wade Hands and Uskali Mäki (eds.), The Handbook of Economic Methodology. Cheltenham: E. Elgar, 304-307.

. 1999. "The formalist revolution or what happened to orthodox economics after world war II", in Roger Backhouse and John Creedy (eds.), From Classical Economics to the Theory of the Firm. Essays in Honour of D. P. O'Brien, Cheltenham: E. Elgar, 257-280.

. 2001. "No history of ideas, please, we're economists." Journal of Economic Perspectives, 15(1): 145-164. 
2002a. "Is there really progress in economics?", in Stephan Boehm, Christian Gehrke, Heinz D. Kurz and Richard Sturn (eds.), Is There Progress in Economics. Knowledge, Truth and the History of Economic Thought, Cheltenham: E. Elgar, 21-41. 2002b. "Ugly currents in modern economics", in Uskali Mäki (ed.), Fact and Fiction in Economics. Models, Realism and Social Construction, Cambridge: Cambridge University Press, 35-56. . 2003. "The formalist revolution of the 1950s", Journal of the History of Economic Thought, 25(2): 145-156.

.2009a. "The trade-off between rigor and relevance: Sraffian economics as a case in point", History of Political Economy, 41(2): 219-247.

Bonanno, Giacomo and John Vickers. 1988. "Vertical separation", Journal of Industrial Economics, 36(3): 257-265.

Boumans, Marcel. 2012. "Mark Blaug (1927-2011). An unrepentant Lajatosian”, History of Economic Ideas, 20(1): 11-24.

Cartwright, Nancy. 1991. "Replicability, reproducibility, and robustness: Comments on Harry Collins", History of Political Economy, 23(1): 143-155.

Collins, H.M. 1991. "The meaning of replication and the science of economics", History of Political Economy, 23(1): 123-142.

Davis, John B. 2012. "Mark Blaug on the historiography of economics". Available at http://ssm.com/abstract=2094422.

Frigg, Roman and Stephan Hartmann. 2009. "Models in Science", in Edward N. Zalta (ed.), The Stanford Encyclopedia of Philosophy (Summer 2009 Edition), URL = http://plato.stanford.edu/archives/sum2009/entries/models-science/

Gabszewicz, Jean J. and Jacques-François Thisse (eds.). 1999. Microeconomic Theories of Imperfect Competition. Cheltenham: E. Elgar.

Gibbard, Alan and Hal Varian. 1978. "Economic models", Journal of Philosophy, 75(11): 664-677 [Reprinted in Bruce Caldwell (ed.), The Philosophy and Methodology of Economics, Cheltenham: E. Elgar, 1993, Vol. III: 401- 414].

Gilboa, Itzhak, Andrew Postlewaite, Larry Samuelson, and David Schmeidler. 2012. "Economic Models as Analogies", PIER Working Paper 12-001, http://ssrn.com/abstract=1979472

Hands, D. Wade. 1985. "Second thoughts on Lakatos", History of Political Economy, 17(1): 1-16.

1990. "Second thoughts on 'Second thoughts': reconsidering the Lakatosian progress of the General Theory', Review of Political Economy, 2(1): 69-81. Press.

Knorr-Cetina, Karin. 1991. "Epistemic cultures: Forms of reason in science", History of Political Economy, 23(1): 105-122.

Kreps, David M. and Scheinkman, José A. 1983. "Quantity precommitment and Bertrand competition yield Cournot outcomes", Bell Journal of Economics, 14(2): 326-337 [Reprinted in Gabszewicz and Thisse, 1999, 105-116]. 
Kuorikoski, Jaakko, Aki Lehtinen and Caterina Marchionni. 2010. "Economic modelling as robustness analysis", British Journal for the Philosophy of Science 61(3): 541-567.

Levins, Richard. 1966. "The strategy of model building in population biology", American Scientist, 54(4): 421-31.

-1968. Evolution in Changing Environments. Some Theoretical Explorations, Princeton, NJ: Princeton University Press.

de Marchi, Neil and Mark Blaug, eds.. 1991. Appraising Modern Economics. Studies in the Methodology of Scientific Programs, Aldershot: E. Elgar.

Pagnozzi, Marco and Salvatore Piccolo. 2012. "Vertical separation with private contracts", Economic Journal 122(559): 173-207.

Salanti, Andrea. Forthcoming. "'Rigor' vs. 'relevance' in economic theory: A plea for a different methodological perspective", History of Political Economy.

Weisberg, Michael. 2006a.’Robustness analysis”, Philosophy of Science 73(5): 730-742. - 2006b. "Forty years of 'the strategy': Levins on model building and idealization", Biology and Philosophy, 21(5) :623-645.

Wimsatt, William C. 1981. "Robustness, reliability and overdetermination", in M. B. Brewer and B. E. Collins (eds.), Scientifc Inquiry and the Social Sciences, San Francisco: Jossey-Bass, 124-163.

- 1987. "False models as means to truer theories", in M. H. Nitecki and A. Hoffman (eds.), Neutral Models in Biology, , Oxford: Oxford University Press, 33-55.

Woodward, Jim. 2006. "Some varieties of robustness", Journal of Economic Methodology 13(2): 219-240. 


\section{"Rigor" vs. "Relevance" in Economic Theory: A plea for a Different Methodological Perspective*}

\section{Introduction}

Since the publication of Blaug (1975), disputes between the late Mark Blaug and a number of Sraffian scholars about the importance of Sraffian economics have cyclically recurred. On one occasion (cf. Blaug 1999a and 2002a, Garegnani 2002, and Kurz and Salvadori 2002), the discussion was mainly centered on the correctness of the so-called surplus approach (as set forth, for instance, in Garegnani 1987 and 1998) to the interpretation of classical economics: an issue which is undoubtedly in the right place within the realm of the history of economic thought.

In other two occurrences (cf. Blaug 1991 and 1995 versus Steedman 1991 and 1995, and, more recently, Blaug 2009, Kurz and Salvadori 2010 and 2011, Garegnani 2011) the main issues at stake can be regarded as essentially methodological. The bone of contention in this respect may be portrayed as a fundamental disagreement about the importance to be assigned to logical coherence versus empirical importance in appraising economic theories ${ }^{1}$.

To put it in slightly different terms, the main question becomes if, and if so, why, in economics we should face an apparent trade-off between logical rigor and empirical relevance: a question that of course does not apply to the sole "case in point" of Sraffian economics $^{2}$. Not surprisingly, therefore, the target of Blaug's most recent criticism includes

\footnotetext{
* Previous versions of this paper have been presented at the $9^{\text {th }}$ annual meeting of Storep, Minervino di Lecce, 9-11 June 2011 and at the $9^{\text {th }}$ INEM Conference, Helsinki, 1-3 September 2011. I wish to thank the participants in these conferences, as well as Kevin Hoover and two anonymous referees, for providing helpful comments. The present version is forthcoming in History of Political Economy.

${ }^{1}$ As noted by Backhouse (1995, 32-3), "Blaug criticizes Sraffian economics for being empirically empty and failing to produce any interesting testable predictions, and Sraffian economists for attaching greater weight to logical consistency than to real world relevance". Steedman's rejection of such a critique could not have been more biting: "Given the clearly stated purpose of Sraffa's book, it is quite inappropriate for Blaug ... to complain of its lack of empirical implications, or of Sraffa's giving priority to logical rigour over practical relevance" (1995, 8, italics in the original).

${ }^{2}$ The original motivation for this paper was indeed provided by seeing Salanti (2001) to be approvingly quoted by Mark Blaug (2009, 238, n. 32) in support of his own indictment of Sraffian economics for its lack of interest in (and/or of relevance for) empirical research. Actually, what I was trying to say there, within the limited space of a book review, was that the famous controversies on
} 
also a huge amount of leading economic theories (notably general equilibrium theory, the first fundamental theorem of welfare economics, the Coase theorem, some results in game theory, etc.), so that two of the currently most active and prolific scholars in the Sraffian camp, in their punctual and lively reaction, wonder "what prompted Blaug to choose the title of his piece" (Kurz and Salvadori 2010, 3).

However, apart from the appropriateness of the title or of Blaug's arguments therein about the alleged "case in point", his discussion of a perceived trade-off between rigor and relevance cannot be simply dismissed as a "trite contradistinction ... popular with some economists (and especially with undergraduates) ... [and] typically invoked by those who emphasize the relevance of what they are doing but do not insist on the rigor with which is done" (Kurz and Salvadori 2010, 3 and 2011, 609). Similarly, their conclusion according to which: "[I]t is obvious that an economic analysis that rightly wishes to gain respect should seek to be both rigorous and relevant" (Kurz and Salvadori 2010, 16 and 2011, 615) appears not to be so plainly obvious ${ }^{3}$.

Such a judgment ends up by diverting the attention from the necessity of better characterizing the notions of rigor and relevance, the appropriate methodological framework within which to place the discussion of the relationship between them, and the possible implications of the alleged trade-off. It conceals, among other things, the plain fact that the question of "rigor" versus "relevance" in economic theorizing is one of the specters which have continuously haunted methodological appraisals of economics, even when not explicitly addressed in such terms, since (at least) Methodenstreit or Marshall's methodological qualms (see Barkai 1996 and Hodgson 2005, respectively ) and more recently reiterated by a number of serious scholars from different perspectives ${ }^{4}$, not to mention that a quite different attitude is

\footnotetext{
capital theory and related issues between the two Cambridges were made possible by a shared methodological perspective about the scope of "pure" economic theory, common in many respects to both sides of the debate (for a more detailed discussion on this point, let me refer to Salanti 1989).

${ }^{3}$ Let me guess, in all fairness to the authors, that they might have been induced to write down such offhand pronouncements just for the sake of controversy. In other circumstances (see, for example, Kurz and Salvadori 2005, Salvadori and Signorino 2007 and 2010) they have indeed proved to be more cautious and careful in dealing with methodological issues.

${ }^{4}$ Steindl $(1965,18)$, for example, reports "an old epigram of Professor Kalecki in his characteristic vein (quoted without permission): 'Economics consists of theoretical laws which nobody has verified and of empirical laws which nobody can explain"” For recurring lamentations see also, among others: Leontief (1971), Gordon (1976), Mayer (1993), and Lipsey (2001). More recently, the evident inability of current (orthodox) macroeconomics to predict, let alone to advocate efficacious remedies,
} 
taken by philosophers of science (particularly by those interested in economic methodology). One of the most explicit statements in this last respect can be found in Cartwright (2007, 218): "The method of verification is deduction: we know what does happen in one of these economies because we know what must happen given our general principles and the characteristics of the economy. We are, however, faced with a trade-off: we can have totally verifiable results but only for economies that are not real."

Consequently, the aim of this paper is to show that the recent debate between Mark Blaug (2009) and Heinz Kurz and Neri Salvadori (2010) on the relevance of Sraffian economics suffers, in one way or another, from relying on some outmoded approaches to the philosophy of science. If we instead adopt the perspective of the so-called "semantic view" of theories, the trade-off between rigor and relevance emerges as a possible trait of a large portion of models in many scientific disciplines, and economics, at least in this respect, is no exception at all.

\section{What is meant by "relevance"?}

It should be generally agreed that before discussing the existence (or non-existence) of any trade-off, one should be able to define, at least with tolerable precision, the two (or more) involved magnitudes. In this respect a major difficulty usually arises as far as the notion of relevance is concerned and Blaug (2009) does not make an exception: what he exactly means by relevance is unclear from several points of view. ${ }^{5}$

the 2008 financial crisis motivates contentions like the following: "Faced with the choice between rigorous models based on questionable assumptions and what might be termed 'messier' theories based on more realistic assumptions, most macroeconomists have opted for the former." (Backhouse 2010, 136).

${ }^{5}$ This is not to say, however, that concerning 'rigor' there are not problems as well. Blaug $(2009,220)$ suggests a threefold classification of mathematical modelling in economics, that is: $i$ ) axiomatic theoretical constructions "starting from some intuitively plausible axioms and then deriving all of [their] theorems employing nothing more than deductive logic"; ii) models whose (equilibrium) solution for endogenous variables stem from "the simultaneous equation method"; iii) mathematically "structured models" of the type we may found in growth theory. One of the problems with this characterization is the partial overlapping among the envisaged categories, in the sense that a particular model might fit in more than one of them (e.g. Debreu 1959). All in all, however, such hints are sufficient to exemplify the different forms under which the 'formalist vice' materializes within the discipline. For previous expressions of concern about the excessive inclination towards formalism in modern economics, stemming from a similar standpoint, see Ward (1972), Blaug (1999b), and Hutchison (2000, chapters 8-10). 
Indeed, scattered through his paper, we may come across at least four different accounts of what relevance might mean. At first we are told that:

Relevance is not a matter for individual opinion but a social judgment of the community of professional economists. We assess that judgment by inspecting the professional literature, by citation counts, or by any of the other method of bibliometrics. (221).

Apart from that bibliometric methods might end up by supporting precisely those leading economic theories which are among the targets of his criticism as well, a few pages later irrelevance is portrayed as inability to deal with "problems deemed to be socially, politically, or historically relevant" (226). As a result, it remains somewhat undecided which community should be in charge of delivering the definitive verdict: is it the invisible college of professional economists or the public opinion in general?

Admittedly, the notion of relevance is undoubtedly difficult to characterize with precision, so that Blaug cannot be blamed too much for his somewhat contradictory attempt to define it. In any case we have to notice that, according to his own methodological stance, he ends up by indicating as "relevant" an incredibly restricted subset of what is usually regarded as valuable research in economics: "The trade-off between rigor and relevance is pervasive throughout economics and it is avoided only in one or two extreme examples." $(2009,224)$, where the main example is given by Arrow's impossibility theorem.

This essentially happens because some methodological tenets more or less implicitly endorsed by Blaug are ill-suited to deal with economic theory (and economists' practice, for that matter). Indeed, in the same paper, we find allusions to the possibility of "assessing the fecundity of a theory by its ability to explain stylized facts, meaning easily observed and wellattested empirical regularities about an economy or an economic system" (239), as well as to "empirical work inspired by the theoretical ideals" (238). These two unqualified allusions to empirical work raise some further questions about the intended scope of applied research in economics. First, the two suggestions do not go in the same direction: building models in order to provide theoretical explanations for some stylized facts is a kind of activity quite different from looking at data in order to find empirical support to our preferred theoretical ideals.

Anyway, judging from some of Blaug's previous writings, one could think of testing theories in the sense of Popperian falsificationism (Blaug 1994), or making predictions about 
relevant economic phenomena ${ }^{6}$. In both cases, however, we can detect an implicit reliance on the so called "symmetry thesis" (in fact explicitly endorsed by Blaug 1992, 5-10) and the consequent position in favor of the possibility of thinking about models of scientific explanation ${ }^{7}$. A slightly different version of the same idea characterizes scientific explanation as a hypothetical-deductive argument. It is commonly referred to as the deductivenomological (D-N) model of scientific explanation, due to Carl Hempel and usually presented as a deductive inference starting from a set of premises supplemented by at least one "universal law" (explanans) in order to obtain, through deductive inference, the proposition to be explained (explanandum). According to Hempel (1965, 247-248) such a kind of inference must satisfy the following conditions:

Logical conditions of adequacy:

(R1) The explanandum must be a logical consequence of the explanans [...]

(R2) The explanans must contain general laws and these must actually be required for the derivation of the explanandum [...]

(R3) The explanans must have empirical content; i.e. it must be capable, at least in principle, of test by experiment or observation [...]

Empirical conditions of adequacy:

(R4) The sentences constituting the explanans must be true.

Note that according this perspective rigor (if only in the sense of logical correctness) and empirical relevance (intended at least as factual truthfulness) should go hand in hand, simply because both of them are included among the required "conditions of adequacy" for scientific explanations. It should be obvious, therefore, that from this standpoint the problem of a possible trade-off between rigor and relevance, however defined, could never take place ${ }^{8}$.

\footnotetext{
6 "Economic hypotheses can be judged by their logical coherence, their explanatory power, their generality, their fecundity, and, ultimately, their ability to predict. Why are economists concerned at all with predictability? Because it is the ultimate test of whether our theories are true and really capture the workings of the economic system independently of our wishes and intellectual preferences" (Blaug 2002b, 49)

${ }^{7}$ As Rudolf Carnap (1966, 6-16) aptly summarizes it: "[R]egularities are expressed by statements called "laws". [...] What purposes do they serve in science and in everyday life? The answer is twofold: they are used to explain facts already known, and they are used to predict facts not yet known. [...] The general schema involved in all explanations can be expressed symbolically as follows: 1. (x)(Px $\supset$ Qx) 2. Pa 3. Qa The first statement is the universal law that applies to any object $\mathrm{x}$. The second statement asserts that a particular object ' $\mathrm{a}$ ' has the property $\mathrm{P}$. These two statements together enable us to derive logically the third statement: object ' $a$ ' has the property Q. [...] This schema underlies both explanation and prediction; only the knowledge situation is different ... In explanation the fact Qa is already known ... In prediction, Qa is a fact not yet known.

${ }^{8}$ This is the main reason why logical empiricists were never persuaded by Friedman's (1953) praise for unrealistic assumptions: see, for example, Nagel (1963).
} 
The notion of scientific explanation purported by the previous quotations belongs to the so called "received view" of theories, according to which scientific theories should be understood as syntactical structures whose logical (possibly axiomatic) calculi, theoretical terms, and related sentences are partially interpreted by means of correspondence rules in order to link them with the observational content of theories. For a number of reasons, such a conception of scientific theories went under attack and was finally abandoned by philosophers of science some decades ago 9 .

Apart from that, if we try to appraise economic theories according to the D-N model of scientific explanation, we soon realize that general laws suited for the role of "covering laws" are conspicuously lacking. In economics what bears a sufficient resemblance to the D-N model is what has been called situational determinism ${ }^{10}$, according to which most economic reasoning is embedded in models with the rationality principle as the one and only everpresent covering law. Advocates of situational determinism maintain that the explanans typically includes hypotheses (assumptions) about the envisaged situation, as well as agents' consciousness of such a situation and the kind of behavior that would be appropriate (rational) in such circumstances, together with the rationality principle, asserting that agents always act rationally (i.e. adequately or appropriately to the situation) ${ }^{11}$. Note, however, that we know the rationality principle to be empirically false, so that, if we wanted to preserve the basic tenets of falsificationism, we ought to shelter it from potentially falsifiable attempts. In Popper's (1994, 169-179) words:

The adoption of the rationality principle can therefore be regarded as a by-product of a methodological postulate. It does not play the role of an empirically explanatory theory, of a testable hypothesis. For in this field, the explanatory theories or hypotheses are rather our various models, our various situational analyses. It is these which may be empirically more or less adequate - which may be discussed and criticized, and whose adequacy may sometimes even be tested, thereby enabling us to learn from our mistakes.

What about general economic laws other than the rationality principle? One of the most popular answers is exemplified by the following passage in Sutton $(2000,4)$ :

\footnotetext{
${ }^{9}$ Cf. Suppe (1972, 1977, and 2000).

${ }^{10} \mathrm{Cf}$. Latsis (1972) and (1976). For a critical assessment of this early episode in the recent history of economic methodology, see Mäki (2008).

${ }^{11}$ Nowadays we are accustomed to characterize the rationality principle in terms of maximization or consistency. It has not to be forgotten, however, that these particular specifications need to be grounded on the vaguely defined but fundamental principle of rationality as traditionally understood in the different epochs of the history of economics: cf. Lagueux (2004).
} 
[E]conomic mechanisms work out their influences against a messy background of complicated factors, so that the most we can expect of economic analysis is that it captures the "tendencies" induced by changes in this or other factor.

Usually such a "messy background" is tackled by means of some ceteris paribus (or even ceteris absentibus) clauses in order to isolate the specific mechanism which is dealt with. In that way we can identify an impressive array of "tendencies", but simple rules of composition for different mechanisms contemporarily at work do not abound in the economists' standard tool-box. As a result, we may have a first possible source of a trade-off between rigor and relevance: isolation made possible by clauses of this kind allows being more rigorous than otherwise, but they can also be a hindrance for the empirical validity of the conclusions so obtained. As Boumans and Morgan $(2001,14)$ put it:

The advantage of the use of the ceteris paribus pound was that the issues could be handled 'more exactly'. But it had the disadvantage, noted by Marshall, that the more the issue was narrowed 'the less closely does it correspond to real life' (Marshall 1964[1890], $304)^{12}$

\title{
2. On the role of models: a different perspective
}

Another tenet of the received view was a certain disdain for the role of models in science ${ }^{13}$; this because logical empiricists regarded scientific theories mainly as collections of sentences susceptible of logical analysis and the related models as having at most a heuristic role to play. One of the consequences of its dismissal has been a renewed interest in the role of models in the various scientific fields. As Contessa $(2010,193)$ aptly remarks:

\begin{abstract}
After the decline and fall of the syntactic view, the fortunes of scientific models in philosophy of science changed dramatically. On the semantic view of theories [...] scientific theories are collections of models, which are the objects that satisfy the axioms of the theory and two sets of axioms are two formulations of the same theory if the same set of models satisfies them both [...]. On the 'models-as-mediators' view, which today is the main alternative to semantic view, scientific theories are not collections of models; models mediate between abstract theories and concrete systems in the world.
\end{abstract}

A widely held commonsensical view of models looks upon them as simplified/stylized representations of (some features of) the "real world" that can be "manipulated" in order to

\footnotetext{
${ }^{12}$ See also Boumans (2005).

${ }^{13}$ For a summary of how the perspective on models among the philosophers of science changed over time, see Bailer-Jones (1999). For a good introduction to the recent philosophical literature on the various roles that models play in scientific practice, see Frigg and Hartmann (2006).
} 
understand some "mechanisms", supposed to be at work within the model as well as in the world out there. Two problems immediately arise in this respect: how to construct useful models and how to interpret them. Building a model is a matter of selecting the appropriate scope, level of detail, and issues to be emphasized. Of course there is no set formula to do this, because the appropriate levels of each depend on what the model seeks to accomplish.

In any case, either if we look at models according to the "models-as-mediators" standpoint, or whether we adopt the perspective of the so called semantic view of theories ${ }^{14}$, we may agree that models have to accomplish some representational functions. In this respect, while the two approaches hold a different view about the definition of theories, as far as models are concerned the two perspectives are not far apart. Indeed, as noted by Frigg and Hartmann $(2009,2)$,

Models can perform two fundamentally different representational functions. On the one hand, a model can be a representation of a selected part of the world (the 'target system'). Depending on the nature of the target, such models are either models of phenomena or models of data. On the other hand, a model can represent a theory in the sense that it interprets the laws and axioms of that theory.

The same idea has been effectively put in graphic form by Ronald Giere (see Figure 1 below).
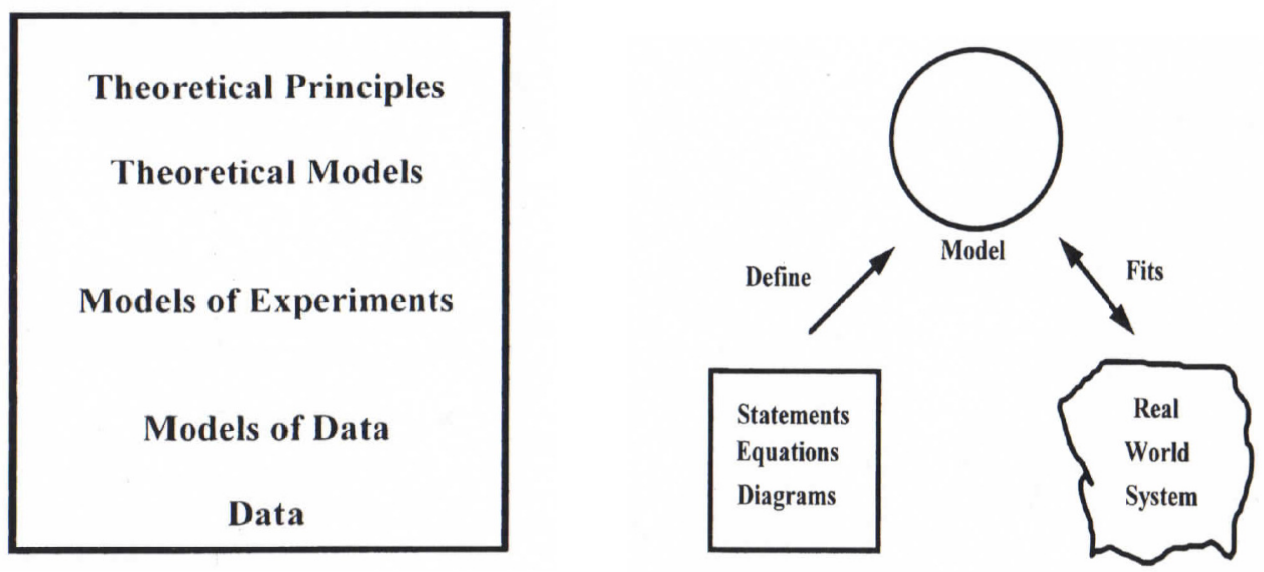

Figure 1. Excerpted from Giere $(1999,54-55)$

\footnotetext{
${ }^{14}$ The "models-as-mediators" view regards models as mediating entities between abstract theories and concrete systems in the world (see Morgan and Morrison 1999), while according to the semantic view of theories models are the objects that satisfy the axioms of the theory and two sets of axioms are two formulations of the same theory if the same set of models satisfies both of them (cp. Suppe 1989).
} 
Note that the two senses in which a model can be said to have a representational function (that is, with reference either to a theoretical framework or to a target and/or real world system) are not mutually exclusive: models can be representations in both senses at the same time. In other words, as is shown in Figure 1, a justification is necessary in order to offer good reasons for believing that what happens within the model holds also outside it (that is, with reference to those phenomena in the real world we are trying to "understand" by means of that model).

Such a possibility is precisely the source of a potential trade-off between rigor and relevance. Rigor is a matter of being consistent with theoretical principles, while relevance has to do with the possibility of transferring conclusions or predictions obtained within the model to what actually happens in the external world ${ }^{15}$.

We cannot, however, identify sic et simpliciter the "target system" of a specific model with the world "out there". Every single economic model is at most a representation of a selected part of the world, or of some economic mechanisms which we hope to identify within a complex framework of interrelated factors. In order to deal with such a complexity a continuum of different modeling strategies has been developed throughout the history of economics.

At one end of the spectrum we may find models in the realm of "pure theory", such as general equilibrium or Sraffian accounts of the fundamental determinants of prices. Here analytical rigor and deduction from first principles mainly aim at representing, as exactly as possible, theoretical principles. Models obtained in that way, however, cannot but be too abstract for immediate empirical applications. In this case a trade-off between rigor and relevance occurs since the possibility of successive approximations is hampered by the absence within economics of something equivalent to the (parallelogram) rule for calculating the resultant of different forces acting together on a body.

At the other end we find an array of subdisciplines (like, for instance, macroeconomics) where the need for sound predictions is pretty urgent. Here theoretical rigor is all too often

\footnotetext{
${ }^{15}$ It should be noted, however, that the possible linkages between the model and its (empirical) target are seen as more problematic than in traditional verificationist o falsificationist approaches. Here emphasis is placed on the idealisations and abstractions within the model on one side, and on the non demonstrative patterns of reasoning that we usually encounter when dealing with the external validity of the model.
} 
sacrificed on the altar of applied econometrics: think of, for instance, the recurring criticisms concerning the doubtful theoretical foundations of the aggregate production function or the representative agent.

In the middle, so to speak, we may find a number of other fields of research whose scope is somewhere in the middle between the previous two. Models of this sort have been recurrently justified by different methodological standpoints, from Friedman's advocacy of "as if" to Gibbard and Varian (1978) view of "models as caricatures". More recently, a number of scholars interested in economic methodology have suggested that there is a similarity between these models and experiments. The idea is that, in a mainly non experimental science like economics, models play a role similar to that played by experiments in other sciences. ${ }^{16}$ Among economists, such an interpretation of the role of models had been forcefully advocated by Robert Lucas since the early 1980's. The following sentences, for instance, are very explicit in this respect:

One of the functions of theoretical economics is to provide fully articulated, artificial economic systems that can serve as laboratories in which policies ...can be tested out at much lower cost. [...] On this general view of the nature of economic theory, then, a 'theory' is not a collection of assertions about the behaviour of the actual economy, but rather an explicit set of instructions for building a parallel or analogue system - a mechanical imitation economy. (Lucas 1980, 696-7).

At that time, the controversial nature (at least among economic methodologists, if not among macroeconomists) of his main theses in macroeconomics probably prevented a wider acceptance of his methodological insights, but this should not preclude us to recognize some merits to them. In the words of Nancy Cartwright $(2007,218)$ :

Lucas is a good spokesman in favour of this kind of theorizing, and that is why I cite him. But the method is in no way peculiar to his point of view. Modelling by the construction of analogue economies is a wide spread technique in economic theory nowadays; in particular, it is a technique that is shared across both sides of the divide between microand macroeconomics.

If the role of model is considered according to this perspective, the existence of a tradeoff between rigor and relevance becomes an occurrence to be expected. Concerning experiments, it is indeed generally agreed that an improvement in their internal validity in most circumstances brings about an impairment of their external validity, and the same thing

\footnotetext{
${ }^{16}$ See, for example, Faverau (1997), Morgan (2002), Guala (2005), Mäki (2005), Cartwright (2007, chapter 15).
} 
is likely to occur as far as models are concerned. This happens because the structures of "analogue economies" must be suited for exact deductions (and, possibly, feasible exercises in applied econometrics), but what is good for these endeavors does not necessarily prove to be also a good representation of what takes place in real economies.

\section{The "case in point" of Sraffian economics}

It should be generally agreed that the theoretical core of what is commonly referred to as Sraffian economics is given by Sraffa's 1960 analysis of prices of production, together with subsequent amendments, refinements, and extensions we may find in the secondary literature on this subject. Rigor is obtained by means of a model where we have fixed quantities (or, assuming linear production functions à la Leontief, fixed coefficients of production), a uniform rate of profit (and possibly uniform rates of compensation for the other primary inputs), so that relative prices are determined such as to be compatible with the reproduction of the system.

Concerning relevance, the crucial question is what the corresponding target in the real economies of such a theoretical construct might ever be. One common answer, as Kurz and Salvadori $(1995,1)$ put it, proceeds as follows:

These economic systems and the corresponding prices are to be understood as reflecting characteristic features of a capitalist market economy in an ideal way: they express the pure logic of the relationship between value and distribution ...

The classical as well the early neoclassical economists did not consider these prices as purely ideal or theoretical; they saw them rather as 'centers of gravitation', or 'attractors', of actual or market prices.

However, in order to regard prices of production as "centers of gravitation", we should recognize that the whole argument implies the adoption of the classical notion of competition, which in its turn rests on the existence of a mechanism of capital mobility among different "industries" that would eventually drive the system towards the general realization of a uniform rate of profit. The rationale of focusing attention on natural prices is provided by the assumption that the forces which determine them are the more systematic and persistent and therefore, in the long-run, dominate the transitory and unsystematic ones (that is, those responsible for the fluctuations of market prices around their centers of gravitation) ${ }^{17}$.

\footnotetext{
${ }^{17}$ See Garegnani (1976 and 1987). Similar contentions can be found in a number of other entries collected in Eatwell, Milgate and Newman (1987) such as: "Competition: Classical Conceptions" and
} 
Apart from that formal proofs of stability of models which try to capture the basic elements of the notion of classical competition under sufficiently general conditions have yet to be provided, a condition for their possible usefulness is that changes in the data should be slower than movements along the trajectories of the state variables of the dynamical system. This is undoubtedly somewhat discouraging: while in the real systems "data" change whenever a wage settlement occurs, a new technique is introduced in the system, a tax is modified, and so on, at the same time we have no precise idea about the rate of the adjustment process or the time requested to overcome any kind of market frictions. If only for this reason, therefore, we may well suspect that the so much celebrated rigor of Sraffian analysis has been obtained at the cost of a very limited scope when we try to employ it to say something useful about real economic systems ${ }^{18}$.

\section{Final remarks}

All the previous discussion is not meant to provide definitive evidence of a necessary existence of a trade-off between rigor and relevance in economics, which, however, is probably impossible to be conclusively demonstrated. More modestly, I tried to show that those who argue in favor of an economic analysis "both rigorous and relevant" have (at least) to bear the burden of the proof of the possibility of what they are advocating with so much confidence. Surely Sraffa would not have tolerated any trade-off between logical rigor and empirical relevance, but he would have been equally uneasy with a theory divorced from "facts". Indeed, his famous criticism of Marshallian economics can be read as an attempt to reconstruct in a logically consistent way Marshallian partial equilibrium models, in order to single out the logically admissible accounts of empirical situations to which those models could be applied and those situations to which they could not. In any case the issue of "rigor vs. relevance" in economics undoubtedly deserves further methodological scrutiny, and the recent methodological approaches previously hinted at in section 2 will probably provide some appropriate conceptual tools.

\footnotetext{
"Natural and Normal Conditions" by J. Eatwell, "Equilibrium: Development of the Concept" by M. Milgate, "Long-Run and Short-Run" by C. Panico and F. Petri, "Natural Price" by G. Vaggi.

${ }^{18}$ For a more detailed discussion of some methodological aspects of the notion of "long-period positions", let me refer to Salanti (1990). Blaug (1999a, 231 and 2009, 226-229) raises similar points. $\mathrm{He}$ is more concerned, however, with stressing the methodological similarity between Sraffian economics and general equilibrium theory.
} 
Finally, we should observe that, although the bone of contention between Blaug and his Sraffian opponents is apparently the relevance of Sraffian economics, it actually involves a different judgment on the usefulness of Marshallian economics. On one side, indeed, Blaug (2009, 241-242) could not have been more explicit in saying that:

Is there no alternative to either Debreu or Sraffa? Of course, there is. I am not advocating loose thinking as a replacement for rigor but rather Marshallian partial equilibrium analysis that tackles local questions in a subset of economic relationships, taking account of as many interdependencies in the economy as possible but always favoring practical results rather than logical generalities, keeping close to what can be quantified and measured. [...] The upshot is an analysis of the workings of an economic system that is systematic, free of logical contradictions, but not necessarily rigorous in a mathematical sense, remaining judgmental and qualitative. ${ }^{19}$

On the other side, as is well known, Sraffians generally go along with the trenchant evaluation of Marshallian theory in the final sentences of Sraffa's (1930) rejoinder to Dennis Robertson in the famous symposium on increasing returns, where the Italian scholar is extremely clear in pointing out that:

We [P. Sraffa and D. Robertson] seem to be agreed that the theory cannot be interpreted in a way which makes it logically sell-consistent and, at the same time, reconciles it with the facts it sets out to explain. Mr. Robertson's remedy is to discard mathematics, and he suggests that my remedy is to discard the facts; perhaps I ought to have explained that, in the circumstances, I think it is Marshall's theory that should be discarded.

Basically, what comes out from the previous quotations is that the failure to combine rigor and relevance is employed as a criticism of the opponents' favored theoretical approach by both sides of the debate. In so doing, however, they end up by conveying to the neutral reader the erroneous impression that the whole discipline of economics suffers from a generalized inability to offer rigorous and at the same time relevant conclusions. While it is true that we have no simple tools suited to gain cumulative knowledge by simply adding up more "realistic" features to our most abstract models, nevertheless we cannot deny that, after all, in the history of economics some elements of progress can be undoubtedly detected.

\footnotetext{
${ }^{19}$ Similar remarks could be already found in Blaug (1999a, 229-230): "It is one thing to give due attention to the interdependencies between markets and the simultaneous determination of output and input prices to escape the logical traps of circular reasoning about critical economic variables, but, in general, to pursue ruthlessly the goal of a watertight, mathematically consistent theory of price determination is to fall into the type of sterile formalism that has characterized general equilibrium theory in its modern Arrow-Debreu form. [...] I suggest that Marshall knew better: he kept his general equilibrium theory in an appendix and employed the ceteris paribus method of partial equilibrium to practice substantive economics".
} 


\section{References}

Backhouse, Roger E. 1995. Comment: Sraffian Economics and the Capital Controversy. In Moseley 1995, 23-40.

. 2010. The Puzzle of Modern Economics. Science or Ideology? Cambridge and New York: Cambridge University Press.

Bailer-Jones, Daniela M. 1999. Tracing the Development of Models in the Philosophy of Science. In Model-Based Reasoning in Scientific Discovery, edited by Lorenzo Magnani, Nancy J. Nersessian and Paul Thagard. Dordrecht: Kluwer, 23-40.

Barkai, Haim. 1996. The Methodenstreit and the Emergence of Mathematical Economics. Eastern Economic Journal 22.1:1-19.

Blaug, Mark. (1975) The Cambridge Revolution: Success or Failure? , 2nd ed. London: Institute of Economic Affairs.

. 1991. Afterword. In Appraising Modern Economics. Studies in the Methodology of Scientific Programs, edited by Neil de Marchi and Mark Blaug. Aldershot: Edward Elgar, 499-512.

- 1992. The Methodology of Economics. Or How Economists Explain. 2nd ed. Cambridge and New York: Cambridge University Press.

1994. Why I Am Not a Constructivist: Confessions of an Unrepentant Popperian. In New Directions in Economic Methodology, edited by Roger Backhouse. London: Routledge, 109-36.

—. 1995. Reply. In Moseley 1995, 41-4.

1999a. Misunderstanding Classical Economics: The Sraffian Interpretation of the Surplus Approach. HOPE 31.2:213-36.

. 1999b. The Formalist Revolution or What Happened to Orthodox Economics after World War II?. In From Classical Economics to the Theory of the Firm. Essays in Honour of D. P. O'Brien, edited by Roger Backhouse and John Creedy. Cheltenham: E. Elgar, 257-80.

. 2002a. Kurz and Salvadori on the Sraffian Interpretation of the Surplus Approach. HOPE 34.1:237-40.

. 2002b. Ugly Currents in Modern Economics. In Fact and Fiction in Economics. Models, Realism and Social Construction, edited by Uskali Mäki. Cambridge and New York: Cambridge University Press, 35-56.

- 2009. The Trade-Off between Rigor and Relevance: Sraffian Economics as a Case in Point. HOPE 41.2:219-47.

Boumans, Marcel. 2005. Truth versus Precision. In Logic, Methodology and Philosophy of Science: Proceedings of the Twelfth International Congress, edited by Petr Hájek, Luis Valdés-Villanueva, and Dag Westerstahl. London: College Publications, 257-269. Online at SSRN: $\underline{\text { http://ssrn.com/abstract=1433775 }}$

Boumans, Marcel, and Mary S. Morgan. 2001, Ceteris Paribus Conditions: Materiality and the Application of Economic Theories. Journal of Economic Methodology 8.1:11-26. 
Carnap, Rudolf. 1966. Philosophical Foundations of Physics: An Introduction to the Philosophy of Science. New York: Basic Books.

Cartwright, Nancy. 2007. Hunting Causes and Using Them. Approaches in Philosophy and Economics. Cambridge and New York: Cambridge University Press.

Contessa, Gabriele. 2010. Introduction. Synthese 172.2:193-95.

Debreu, Gerard. 1959. Theory of Value: An Axiomatic Analysis of Economic Equilibrium. New Haven: Yale University Press.

Eatwell, John, Murray Milgate, and Peter Newman, eds. 1987. The New Palgrave. A Dictionary of Economics, 4 Vols. London: Macmillan.

Favereau, Olivier. 1997. Economics and Its Models. In Is Economics Becoming a Hard Science?, edited by Antoine d'Autume and Jean Cartelier. Cheltenham: E. Elgar, 12046.

Friedman, Milton. 1953. The Methodology of Positive Economics. In Essays in Positive Economics. Chicago: University of Chicago Press, 3-43.

Frigg, Roman, and Stephan Hartmann. 2009. Models in Science. In The Stanford Encyclopedia of Philosophy (Summer 2009 Edition), edited by Edward N. Zalta. http://plato.stanford.edu/archives/sum2009/entries/models-science/

Garegnani, Pierangelo. 1976. On a Change in the Notion of Equilibrium in Recent Work on Value: A Comment on Samuelson. In Essays in Modern Capital Theory, edited by Murray Brown, Kazuo Sato, and Paul Zarembka. Amsterdam: North Holland, 25-45.

- 1987. Surplus Approach to Value and Distribution. In Eatwell, Milgate and Newman 1987, Vol. IV, 560-574.

1998. Sraffa: The Theoretical World of the 'Old Classical Economists'. The European Journal of the History of Economic Thought 5.3:415-29.

—. 2002. Misunderstanding Classical Economics? A Reply to Blaug. HOPE 34.1:24154.

2011. On Blaug Ten Years Later. HOPE 43.3:591-605.

Gibbard, Alan and Hal Varian. 1978. Economic models. Journal of Philosophy 75.11:664-677

Giere, Ronald N. 1999. Using Models to Represent Reality. In Model-Based Reasoning in Scientific Discovery, edited by Lorenzo Magnani, Nancy J. Nersessian and Paul Thagard. Dordrecht: Kluwer, 41-57.

Gordon, Robert A. 1976. Rigor and Relevance in a Changing Institutional Setting. American Economic Review 66.1: 1-14.

Guala, Francesco. 2005. The Methodology of Experimental Economics. Cambridge and New York: Cambridge University Press.

Hempel, Carl G. 1965. Aspects of Scientific Explanation and Other Essays in the Philosophy of Science. New York: Free Press.

Hodgson, Geoffrey M. 2005. 'The Present Position of Economics' by Alfred Marshall. Journal of Institutional Economics 1.1:121-37. 
Hutchison, Terence. 2000. On the Methodology of Economics and the Formalist Revolution. Cheltenham: E. Elgar.

Kurz Heinz. D., and Neri Salvadori. 1995. Theory of Production: A Long-Period Analysis. Cambridge and New York: Cambridge University Press.

. 2002. Mark Blaug on the 'Sraffian Interpretation of the Surplus Approach'. HOPE 34.1:225-36.

. 2005. Representing the Production and Circulation of Commodities in Material Terms: On Sraffa's Objectivism. Review of Political Economy 17.3:413-41.

- 2010. In Favor of Rigor and Relevance. A Reply to Mark Blaug. MPRA Paper 20530. http://mpra.ub.uni-muenchen.de/20530/

- 2011. In Favor of Rigor and Relevance. A Reply to Mark Blaug. HOPE 43.3:607-16. [A shortened version of Kurz and Salvadori 2010].

Lagueux, Maurice. 2004. The Forgotten Role of the Rationality Principle in Economics. Journal of Economic Methodology 11.1:31-51.

Latsis, Spiro. 1972. Situational Determinism in Economics. British Journal for the Philosophy of Science 23.3:207-45.

—, ed. 1976. Method and Appraisal in Economics. Cambridge and New York: Cambridge University Press.

Leontief, Wassily. 1971. Theoretical Assumptions and Non Observed Facts. American Economic Review 61.1:1-7.

Lipsey, Richard G. 2001. Successes and Failures in the Transformation of Economics. Journal of Economic Methodology 8.2:169-201.

Lucas, Robert E. 1980. Methods and Problems in Business Cycle Theory. Journal of Money, Credit and Banking 12.4.part 2:696-715.

Marshall, Alfred. 1964 [1890]. Principles of Economics, 8th ed. London: Macmillan.

Mayer, Thomas. 1993. Truth versus Precision in Economics. Aldershot: E. Elgar.

Mäki, Uskali. 2005. Models are Experiments, Experiments are Models. Journal of Economic Methodology 12.2:303-15.

- 2008, Method and Appraisal in Economics, 1976-2006. Journal of Economic Methodology 15.4:409-23.

Morgan, Mary S. 2002. Model Experiments and Models in Experiments. In Model-Based Reasoning: Science, Technology, Values, edited by Lorenzo Magnani and Nancy J. Nersessian. Dordrecht: Kluwer, 41-58.

Moseley, Fred, ed. 1995. Heterodox Economic Theories. True or False?. Aldershot: E. Elgar.

Nagel, Ernest. 1963. Assumptions in Economic Theory. American Economic Review 53.2:211-19.

Popper, Karl R. 1994. Models, Instrument and Truth. In The Myth and the Framework, edited by Mark A. Notturno. London: Routledge, 154-84. 
Salanti, Andrea. 1989. 'Internal' Criticisms in Economic Theory: Are They Really Conclusive?. Economic Notes 1:1-15; reprinted in The Philosophy and Methodology of Economics, edited by Bruce Caldwell. Cheltenham: E. Elgar, Vol. III, 445-59.

1990. The Notion of Long Period Positions: A Useful Abstraction or a Platonic Idea?, Political Economy - Studies in the Surplus Approach 6.1-2.95-102.

- 2001, Book review of Heinz D. Kurz, Critical Essays on Piero Sraffa's Legacy in Economics. Economic Journal 111.475:815-6.

Salvadori, Neri, and Rodolfo Signorino. 2007. Piero Sraffa: Economic Reality, the Economist and Economic Theory: An Interpretation. Journal of Economic Methodology 14.2:187209.

- 2010. The Classical Notion of Competition Revisited, MPRA Paper 24572. http://mpra.ub.uni-muenchen.de/24572/

Sraffa, Piero. 1930. Rejoinder (contribution to the Symposium on 'Increasing Returns and the Representative Firm'). Economic Journal 40.157: 89-93.

- 1960. Production of Commodities by Means of Commodities. Prelude to a Critique of Economic Theory. Cambridge and New York: Cambridge University Press.

Steedman, Ian. 1991. Negative and Positive Contributions: Appraising Sraffa and Lakatos. In Appraising Modern Economics. Studies in the Methodology of Scientific Programs, edited by Neil de Marchi and Mark Blaug. Aldershot: Edward Elgar, 435-50.

- 1995. Sraffian Economics and the Capital Controversy. In Moseley 1995, 1-22.

Steindl, Josef. 1965. Random Processes and the Growth of Firms. A Study of the Pareto Law. London: Griffin.

Suppe, Frederick. 1972. What's Wrong with the Received View on the Structure of Scientific Theories?. Philosophy of Science 39.1:1-19.

. 1977. The Structure of Scientific Theories. 2nd ed. Urbana, Ill.: University of Illinois Press. 1998. Philosophy of Science 67.Supplement, Part II: S102-15.

Ward, Benjamin. 1972. What's Wrong With Economics?. London: Macmillan. 